\title{
Collaboration, trouble and repair in multiparty interactions involving couples with dementia or aphasia
}

Christina Samuelsson and Lars-Christer Hydén

The self-archived postprint version of this journal article is available at Linköping University Institutional Repository (DiVA):

http:/ / urn.kb.se/ resolve?urn=urn:nbn:se:liu:diva-140530

N.B.: When citing this work, cite the original publication.

Samuelsson, C., Hydén, L., (2017), Collaboration, trouble and repair in multiparty interactions involving couples with dementia or aphasia, International J ournal of Speech-Language Pathology, 19(5), 454-464. https:// doi.org/ 10.1080/ 17549507.2016.1221448

Original publication available at:

https:/ / doi.org/ 10.1080/ 17549507.2016.1221448

Copyright: Informa Healthcare

http://informahealthcare.com/ 
COLLABORATION, TROUBLE AND REPAIR IN INTERACTIONS INVOLVING COUPLES WITH DEMENTIA OR APHASIA 


\section{Abstract}

Purpose: The aim of the present study was to identify problems with communication with persons with aphasia and persons with dementia in a collaborative interview setting with their significant others. In particular, to compare interactional practises used in order to resolve problems caused by specific symptoms.

Method: Five persons with aphasia and five persons with dementia and their spouses participated in the present study. Interviews were carried out couple by couple, and the interviews had a task-oriented character with a main focus on interactive and communicative aspects rather than on topical content. The interviews were video and audio recorded. All interviews were transcribed according to conversation analytic principles. From the transcriptions categorizations according to previous literature (Watson et al., 1999) was made. Result: The results demonstrated that repair sequences were frequent in interaction involving PWA, and even more so in interaction involving PWD. In general, it was the PWA/PWD that initiated the repair sequence more often than the spouse, thus keeping to the general rule of a preference for self-initiated repair compared to other-initiated repair.

Conclusion: The active involvement of the conversational partners in trouble solving sequences in interaction with PWA/PWD demonstrated in the present study indicates that the interactional style of the conversational partner to PWA/PWD are important. This implies that conversation partner training programmes would be useful both for PWA and for PWD. 


\section{Introduction}

Aphasia is an impairment of language use following brain damage (Code \& Petheram, 2011). Aphasia is an impairment of linguistic processing at the phonological, morphological, lexical semantic or syntactic level which is usually caused by lesions of the left cerebral hemisphere. Depending on the various aphasic syndromes, expressive and receptive language will be impaired in different ways (McNeil \& Pratt, 2001). Dementia, by contrast, is generally considered a result of widespread multifocal pathology, and it involves dissolution of cognitivel function in which language forms an essential feature (Mathews, Obler \& Albert, 1994). There are also dementia diagnoses that share many features with aphasia, such as semantic dementia/semantic primary progressive aphasia (Neary et al., 1998; Kindell et al., 2013). Pursuing research with separate diagnostic groups has made it possible for researchers to study for example correlations between focal brain damages and specific language symptoms. From a clinical point of view how persons with communicative disabilities, like aphasia and dementia, cope in everyday life, is of central importance in order to design effective and relevant intervention (Bourgeois \& Hickey, 2009; Whitworth, Webster, \& Howard, 2014). In order to understand common everyday communicative strategies and how to improve these through clinical intervention it is of interest to focus on what persons with dementia and aphasia have in common rather than on what is specific for each diagnostic group (Clare, 2008; Ylvisaker \& Feeney; 1998). Although different pathological processes cause the communicative disabilities of people with dementia and aphasia, it can be argued that the problems both groups have in everyday life are not that different (Au, Albert \& Obler, 1988):

1.Both groups have been reported to have significant problems with communication,

2. Specific symptoms may be similar across dementia and aphasia, such as word finding difficulties 
3. The problems may be managed by different interactional practises.

The aim of the present study was thus to identify problems with communication with persons with aphasia and persons with dementia in a collaborative interview setting with their significant others. In particular, to compare interactional practises used in order to resolve problems caused by specific symptoms. We suggest that much could be gained in understanding how people with aphasia and dementia adapt to their communicative disabilities in interaction with their significant others in an everyday setting. We propose to do this by comparing interaction in couples with dementia and aphasia through the use of a common theoretical framework: conversations as a collaborative process (Clark, 1996).

\section{Repair, aphasia and dementia}

In conversations involving persons with either aphasia (PWA) or dementia (PWD) one of the most characteristic issues has been shown to be the emergence of troubles or problems when the participants cannot create a shared understanding of utterances in the on-going conversation (Barnes \& Ferguson, 2014). This can be the result of either of the participants having problems with understanding the previous utterance or with producing a new utterance. What is typical of conversations involving PWA and PWD is that many of the troubles are connected to the specific symptoms shown by the PWA or PWD, and to the interactional strategies used by both participants to repair these troubles. Being able to repair trouble is central to the participants being able to continue their interaction - otherwise there will be a "communicative breakdown”.

Among possible interactional practices, people with aphasia often experienced reduced ability to carry out self-repair, and consequently the conversational partner needed to take an active 
role in resolving troubles in interaction involving PWA (Aaltonen \& Laakso, 2010; Barnes \& Ferguson, 2014; Ferguson, 1993; Goodwin, 1995, Oelschlaeger \& Damico, 2003). In interaction involving PWA, repair sequences were often extended over a number of turns and the degree of other involvement was higher than in typical interactions (Ferguson, 1993, Laakso \& Klippi, 1999; Oelschlaeger \& Damico, 2003). Milroy and Perkins (1992) described the collaborative features of repair in interaction involving PWA and they applied a collaborative model of repair proposed by Clark and Schaefer $(1987,1989)$ to interaction involving PWA. From their results, it was concluded that analysis of repair needed to be adapted in order to encompass the complexity of repair in interaction involving PWA (Milroy \& Perkins, 1992).

In contrast to PWA, communication problems in conversations involving persons with dementia (PWD) has been demonstrated to deteriorate with the progression of the disorder and the type of dementia. In more advanced phases of dementia communicative problems may even result in what sometimes could be called communicative breakdowns because collaboration between the participants was not possible due to the fact that the PWD has access to a very limited set of cognitive and linguistic resources (Perkins, Whitworth \& Lesser, 1998). Among interactional practices, collaborative strategies are often more feasible when the PWD is in the early or middle stage of dementia. In one of the few studies of repair involving PWD, Orange, Lubinski and Higginbotham (1996) compared a group of elderly people without dementia, a group of people with early stage dementia of Alzheimer type (EDAT) and a group of persons with middle stage dementia of Alzheimer type (MDAT). The results showed that the percentage of repair was significantly higher for interactions involving both groups of PWD than for interaction involving elderly without dementia. However, troubles were repaired successfully most of the time. It was also demonstrated that partners of 
persons with EDAT used more elaborated repairs than the persons with EDAT themselves, but that the MDAT group repaired more problems than their conversational partner (Orange et al., 1996).

In another study, Watson et al. (1999) compared spontaneous conversations between 10 healthy participants and 10 persons with dementia (of Alzheimer type, many of moderate to severe). The conversations were analysed in order to identify patterns of trouble indicating behaviour, repair trajectory and repair type. Persons with dementia tended to indicate trouble with dysfluency, repetition, lack of uptake and meta-communicative comments such as "we are talking about” and initiate self-repair. The healthy participants often proposed a hypothesis or requested information in the conversations, and they often engaged in both selfand other-repair. In general, Watson et al. (1999) suggest that the healthy participants were more directed towards interaction and thus collaboration compared to the PWD.

The communication problems of PWD - especially when they cause communicative breakdown - may result from caregivers' use of ineffective communication strategies (Orange et al., 1998; Small et al., 2003). However, caregivers may perceive these strategies as helpful in, for example, resolving breakdowns (Orange et al., 1998; Small et al., 2003; Ripich et al., 1998). Savundranayagam and Orange (2013) investigated the relationship between appraisals of communication strategies, and effectiveness in communication through interaction analysis within the trouble-source repair paradigm. It was concluded that the number of matched and mis-matched appraisals of communication strategies varied across stages of dementia, so that the matching of appraisals and effectiveness was more accurate for PWD in early stage than it was for PWD in middle- and late stages. The authors argue that there is a need for education regarding empirically derived evidence-based communication strategies. 
As this selective review of literature about repair in conversations involving PWA and PWD has indicated, there are no studies that compare the repair strategies used in conversations involving PWA with those involving PWD. From a clinical perspective it would be important to compare repair in dementia to repair in aphasia, as this could add knowledge on how the two fields could inform each other.

\section{Collaboration in conversation}

In an early article, Milroy and Perkins (1992) suggested that the collaborative model of Clark and Schaefer (1987) could be used for understanding conversations involving PWA. In the following study this model will be used as a framework for comparing repair work in couples with both PWA and PWD.

A basic premise of this model is that conversations are best seen as joint activities. This implies that participants have some kind of shared intention, are committed to the activity, are mutually responsive to each other, and also mutually supportive (Bratman, 1992; Gilbert, 2009; Tomasello, 2014). When people engage in a joint activity each participant adds something new to their shared knowledge: their common ground (Clark, 1996). Participants add something new through contributions, often in the form of spoken utterances. Each contribution must be understood and accepted by the other participants. The negotiation of contributions is often distributed over a number of turns (Clark and Schaeffer, 1987, 1989; Clark \& Wilkes-Gibbs, 1986, Clark, 1996). The mutual interpretation of the on-going talk is accomplished by the participants through their mutual orientation towards parsing talk into smaller units, and acknowledging understanding or requesting some kind of repair (Schegloff, Jefferson \& Sacks, 1977). Through this collaborative process a shared meaning of the 
conversation is established and added to the common ground. Hence, an essential ingredient in the joint negotiation of meaning and the establishment and maintenance of common ground in conversation is the use of different kinds of feedback signals (Hydén, Plejert, Samuelsson \& Örulv, 2013). These feedback signals may indicate a problem in understanding a contribution and thus in achieving shared meaning. Ultimately this kind of problem may threaten the completion or continuation of the joint activity and hence call for support in order for the participants to be able to pursue their activity. However, in a study of collaborative referencing in interaction between PWA and their routine conversational partners it was demonstrated that the participating pairs used diverse interactional resources collaboratively in order to solve a referential task (Hengst, 2003).

In the conversation, some contributions may be unclear for some reason and need more elaboration. As a consequence of the mutual responsiveness the participants are constantly monitoring not only the other participant/s in order to understand the communicative intentions, but they are also self-monitoring in order to be able to make contributions to the joint activity that actually are useful for other participants. In research on conversational activity the sequence of not accepting a contribution and requesting, for instance, clarification or repetition, is part of what has been called a repair sequence. Going through a repair sequence entailed repairing a contribution in order to make it possible for participants to negotiate and establish a shared meaning of the contribution (Schegloff, Jefferson \& Sacks, 1977). In previous research, it has been argued that some types of repair are preferred compared to others: self-initiated self-repair, i.e. when you correct your self (often within the same turn-of-talk), was the most preferred type, and other-initiated other repair, i.e. when someone else correct what you have just said, was the least preferred pattern (Schegloff et al., 1977). Self-initiated self-repair occurred in three different positions: (i) within the same turn 
as the trouble source, (ii) in the transition from the turn with the trouble source, or (iii) directly after the response from the interlocutor, i.e. in the next turn of the first speaker. Other-initiated repairs were mainly carried out within the turn following the turn with the trouble source (Schegloff et al., 1977). This means that in typical interaction, repair is mostly carried out in three turns.

Through the use of trouble indicating behaviours (or repair initiators), a listener could highlight a point of trouble in either understanding or in producing contributions (Bremer et al., 1987; Ferguson, 1994). Trouble indication behaviours (TIB) could take a number of forms, e.g., “open class” initiations (Drew, 1997) such as “huh” or “what”, lexical initiators, e.g., "who”, or candidate understandings, i.e. proposing possible meanings in the following turn. The different types of trouble indicating behaviours also called for different possible repair trajectories (Barnes \& Ferguson, 2014). Repair sequences ended when the participants accepted the suggested repair (Clark, 1996). Thus, the following sequence of actions could be as follows:

(contribution) $=>$ trouble indication behaviour $(\mathrm{TIB})$ self/other $=>$ repair $($ self/other) $=>$ acceptance (=> new contribution)

In this perspective, TIBs are important feedback signals that the participants may use to indicate the need for repair and in some cases support from the other in order to be able to pursue their joint activity.

In order to investigate how different repair trajectories operate in interaction, the scope of the present study was to describe and analyse repair patterns in interaction involving couples 
where one part has either aphasia or dementia. The aim of this study was thus to compare trouble and repair sequences between persons with aphasia and persons with dementia in interaction in a collaborative interview setting with their significant others.

\section{Method}

\section{Participants}

Five persons with aphasia and five persons with dementia and their spouses participated in the present study. The PWAs were recruited through language groups where they participated, and the PWD were recruited through memory clinics where they had been diagnosed. All participants were invited to participate by their regular clinician or group leader, and after that they were given written information about the study, including a written consent form that was signed by all participants (both PWA, PWD and their spouses). The PWA all had aphasia following a stroke ranging from four to 18 years ago. Inclusion criteria for PWA were aphasia following stroke, no other known neurological diseases, and Swedish as mother tongue. The spouses were almost the same age as the PWA, and they had been married for 32-53 years (Table I). Their spouses did not have any reported language problems. In the PWA group there were four men and one woman, and they were aged between 59 and 75 years (Table I). The PWD all had a dementia diagnosis since 2-3 years ago. Inclusion criteria for PWD were dementia diagnosis, no other known neurological diseases, and Swedish as mother tongue. The spouses were almost the same age as the PWD, and they had been married for 40-60 years (Table I). In the PWD group there were three women and two men, and they were aged between 63 and 84 years (Table I). Their spouses did not have any reported dementia. All participants gave their written consent to participate in the study.

/Insert table I about here/ 


\section{Procedure}

In the present study, interviews were carried out couple by couple. Present at the interview were the PWA/PWD, the spouse, and two researchers/interviewers (one interviewer carried out the interview, and the other was responsible for the recordings). The interviews were similar to traditional semi-structured interviews, however they were task oriented in the sense that we as interviewers stayed rather passive during the interviews and the couples were given a lot of time to elaborate as well as to collaborate when answering the questions. The couples were given three themes to consider and discuss jointly: their shared history as a couple, the course of the aphasia or the dementia, and what they do during an ordinary day. No specific instructions or information was given on the start of the interviews; they all started with "We would like to ask you to tell us about...”. The length of the interviews ranged from 15 to 50 minutes. The participants could choose where they preferred to be interviewed, and for four of the PWA they took place in their homes, for one PWA it took place at the university, and for the PWD they took place at two local geriatric clinics. The interviews were slightly longer for the PWD, at an average 43 minutes, compared to 33 minutes for the PWA (see Table II). The interviews were video and audio recorded. The camera was placed on a tripod a couple of meters from the table, and the audio recorder was placed on the table. All participants agreed to the interviews being video and audio recorded. All interviews were transcribed according to conversation analytic principles (Ochs et al., 1996; see Appendix for transcription conventions). Interactions were video recorded in order to make it possible to analyse non verbal features of the interaction, such as gestures and gaze. For each extract included in this paper, a translation from Swedish into English is provided. From the transcriptions categorizations was made according to previous literature (Watson et al., 1999). 
The transcripts were scrutinized for trouble indications and repair sequences. The identified sequences were categorized for different types of trouble indications, repair, and acceptances, drawing on categories used by Watson et al. (1999). Through this scrutiny, the following trouble indicating behaviours were identified: clarification requests, defined as a request for clarification of something just said, e.g., repetition with rising intonation or "but when did you say it was”; errors, defined as something apparently wrong, most often corrected either by the speaker or by the interlocutor; questions, defined as a question about something, e.g., "what is it”, or as a question about a name, e.g., "what is it called”; and word searches, defined as an apparent lack of words, demonstrated by a pause or a hesitation phenomenon such as "hm”. The repairs were categorized after who made them, either the speaker (self) or the interlocutor (other). Oftentimes, both interlocutors contributed to the repair. The repairs were also categorized according to the following types of repair: Confirmations, defined as a confirming answer to a question or a clarification request, e.g., "yes of course” in response to "is that the one you are talking to"; Corrections, defined as a correction of an apparent error, e.g., "fifteen per cent" as a correction of the previous utterance "fifteen pieces"; candidate understandings, defined as a proposal after a word search or a question, e.g., "what you mean is that the voice is low”; Expansions, defined as a further expansion of a question, e.g., "was it in the autumn then" after an initial question as "was it the eleventh something”; Gives answer, is defined as giving a straight-forward answer to a word search, a question or a clarification request; Negotiation, defined as a negotiation about what the correct repair item should be, e.g., after a correction; Question, defined as a confirming/clarifying question after a correction of an error or an answer to a question, e.g., “wasn’t she” after a correcting “no she wasn’t”; and Repetition, defined as a confirming repetition responding to a clarification request. 
The acceptances were categorized according to two types: Confirmation, defined as a confirmation of the repair, e.g., "yes” after a given answer to a question; and Repetition, defined as a direct repetition of a repairing turn.

\section{Statistical Analysis}

A statistical analysis of relations between the identified categories and diagnosis were conducted using SPSS software (version 22). Basic calculations were based on cross-tables and test of significance (chi square). In addition to the overall measurements, the repair sequences were analysed in detail and classified regarding types of trouble indicating behaviour, repair strategies, and tokens of acceptance. The different repair trajectories were also subjected to statistical analysis with cross tabulation analysis (chi square). Inter rater reliability of $10 \%$ of the material was calculated according to the formula accordances/(accordances + non-accordances), and it amounted to $75.2 \%$, which is considered good approaching excellent (Hallgren, 2012). The final categorization was then made by consensus between the two authors.

The total number of repair sequences was calculated both as a raw figure and as a proportion of the total number of turns in each interview. A turn was defined as a prosodically coherent unit, with no interruptions by other speakers. Minimal contributions such as "mhm” were also tallied as turns. The length of the repair sequences was calculated, as well as the mean length of turns in words (MLT) for the participants with aphasia and dementia. The distribution of turns between the PWA/PWD and their spouses was also calculated (Table II).

/INSERT TABLE II ABOUT HERE/ 


\section{Result}

The length of the interviews varied in the data, the interviews involving couples with dementia were longer than those with aphasia couples. In the material, 120 repair initiations (TIB) were identified out of a total of 5068 turns (14\%). In general, it was the PWA/PWD that initiated the repair sequence more often than the spouse. Since the trouble source mainly belonged to the PWA/PWD this indicates that the participants are keeping to the general rule of a preference for self-initiated repair. TIBs were more frequent among the couples with dementia than amongst couples with aphasia, and more often these TIBs were initiated by the PWD as compared to the couples with aphasia, where the PWA initiated fewer TIBs than PWD (Table III).

The number of turns involved in the repair sequence differed between the diagnostic groups (although this is not statistically significant): couples with dementia used a slightly higher number of turns (mean=6.48) as compared to couples with aphasia $($ mean=4,98) $($ Table II).

\section{/INSERT TABLE III ABOUT HERE/}

In terms of type of TIB that is made, it was shown that "questions" - that is, the PWA/PWD posed a direct question to the other spouse - was most frequently evoked in couples with dementia, while "word search" was most common in couples with aphasia (Table III). It is also notable that clarification requests were not particularly frequent.

If the PWA/PWD took an initiative to a TIB the spouse was involved in almost all repairs, either as the one who made a repair suggestion (50\%), or together with the PWA/PWD in making the repair (43\%), although the PWA/PWD and spouse quite often suggested different 
repairs (37\% of all repairs) (Table IV). In a small number of cases (9\%), the PWA/PWD both initiated a TIB and actually made a repair (self-repair). If the spouse took an initiative to a TIB (13.4\%), the PWA/PWD in most cases suggested a repair (Table IV). These patterns varied with diagnosis: in the aphasia couples the spouse was somewhat more active in responding with a repair initiated by the PWA compared to the dementia couples.

There were some quite consistent patterns with regard to type of TIB and the kind of repair that ensue (Table V). A further analysis showed that errors commonly result in corrections in dementia couples and questions commonly result either in a direct answer or in negotiation about the answer - or sometimes a correction. In aphasia couples, word search commonly resulted in some kind of suggestion, a direct answer, or in negotiations about the word, while errors resulted in corrections.

The most common type of acceptance was confirmation (58.3\%) or repetition (10.8\%) (Table VI). In less than a third of the repair sequences there was no acceptance that could be identified. Most of the acceptances were preceded by either a correction (11) or by negotiation (13) or by the conversational partner giving an answer (5).

\section{Examples}

The most common repair trajectory in interaction involving couples where one of the spouses has a dementia disease was initiated by a TIB in the format of a question posed by the PWD. These questions were typically responded to with a direct answer by the spouse without dementia, and often there was an acceptance in the third turn. This typical type of sequence is illustrated in example 1 . In example 1 the participants are asked to tell the story about how they met. 


\section{Example 1.}

$\mathrm{M}=$ Participant with dementia, $\mathrm{K}=$ his wife, without dementia

20. M: were we nineteen years [or] ((turns to his wife))

21. K:

[yes]we were nineteen((la[ugh]s))so that's a long time ago

22. $\mathrm{M}$ :

[yes]

In line 20, the participant with dementia poses a direct question about how old they were when they met, and his wife responds to this by answering directly followed by laughter (line 21). She also expands the answer by adding that this was a long time ago. Her response is accepted by the PWD in line 22.

For couples where one of the spouses has aphasia the most common repair sequence comprised an initiation by a word search performed by the PWA, followed by a completion by the spouse, accepted by the PWA in the third turn. This type of sequence is illustrated in example 2, which is taken from a section where the couple is telling the interviewer about the closing of a special school for adults with aphasia.

\section{Example 2.}

$\mathrm{M}=$ Participant with aphasia, $\mathrm{K}=$ his wife, without aphasia, $\mathrm{D}=$ =interviewer

231. M: =in [karlskoga] which unfortunately has(.)had to e:((smacks))e:=

232. D: $[\mathrm{m}:]$

233. K: $\quad={ }^{\circ}$ close down ${ }^{\circ}$

234. M: close down yes

Example 2 starts with the PWA searching for a word when he is talking about a school for adults with aphasia (line 231). In the beginning of M's utterance the interviewer makes a back channelling “mm” in overlap with the start of his utterance (line 232). The PWA's wife responds to his word search by proposing “close down” (line 233), which is accepted with a confirming repetition by $\mathrm{M}$ (line 234). 
Another common repair pattern was initiated by an error made by the PWD or the PWA followed by a correction made by the spouse which often is confirmed by the participant who made the error. Errors were more frequently made by PWD than by PWA, and this type of repair sequence is illustrated in example 3 where a participant with dementia is talking about his doctor, and gets corrected by his wife.

Example 3.

$\mathrm{M}=$ Participant with dementia, $\mathrm{K}=$ his wife, without dementia

427. M: so e:h that mårtensson

428. $\mathrm{K}:{ }^{\circ} \cdot \mathrm{hm}^{\circ}(0.7)$ magnusson

429. M: magnusson

In this example, the PWD makes an error regarding the name of his doctor (line 427), and this is responded to by a hesitating "hm" and a pause preceding a correction from his wife (line 428). The PWD accepts this correction by repeating the correct name (line 429).

Example 1-3 are all examples of repair sequences where the trouble source was resolved within three turns, which is the typical pattern described for interactions where no participant has any communicative disability (Schegloff et al., 1977). In the present material, there were also a number of sequences where the trouble source was not so easily resolved, but rather needed negotiation over longer stretches of turns. For the aphasia dyads $50 \%$ of the repair sequences were longer than three turns, and for the dementia dyads $65 \%$ of the repair sequences were longer than 3 turns. The mean number of turns needed was slightly higher for interactions involving PWD than for interactions with PWA, as described in the quantitative part of the results section. Below follows an example in which a couple where the wife has dementia is asked by the interviewer about the age of their children. The TIB here is a 
question from the PWD about the ages that starts a long negotiation between the spouses about this.

Example 4.

$\mathrm{L}=$ Interviewer, $\mathrm{K}=$ participant with dementia, $\mathrm{M}=$ her husband, without dementia

301. L: [how old are] how old are your children today

302. (2.0) ((M turns towards $\mathrm{K}))$

303. K:((turns towards M but M looks forward)) ((smacks)) yes how old are they

304. (5.1)

305. M: ((eyecontact with $\mathrm{K})$ ) the oldest (0.2) who is in stockholm (was)

306. (0.4)

307. K: yes

308. (0.6)

309. K:[could she be]

310. M:[when did you] when did you get her?

311. (0.7)

312. K: oh well i don't remeber that now[heh]

313. M:

[no] ((eyecontact with K terminated))

314. (1.2)

315. K: no but she must be (2.2)

316. M: she is[born fifty]three

317. K: [sixty]

318. $(0.7)$

319. K: ${ }^{\circ} \mathrm{yes}^{\mathrm{o}}$

320. (0.7)

321. M: one year after we got married (0.2) fiftythree .hh

322. (2.1)

323. K:yes[(xxxxxx)]

324. M: [so she is] fiftyeight years

325. (0.5)

326. K: yeah

327. M: of age

328. (0.7)

329. K: $\mathrm{m}:$

The interviewer poses a question about the age of the children (line 301), and the husband gives the turn to his wife by turning his head towards her (line 302). She responds by asking the question to her husband (line 303), who responds by asking when she had the oldest child (lines 305 and 310). He also adds the information that she lives in Stockholm (line 305). K asks how old she could be in overlap with the question from her husband (lines 307-308), and she concludes that she does not remember in line 312. The discussion continues over several turns, where the couple tries to reason themselves into an answer (lines 315-323), ending in a conclusion by the husband (line 324 and 327), which is accepted by K (lines 323 and 329). 
The length of this sequence seems to be caused by the fact that none of the spouses is able to produce a straightforward answer to the question, possibly due to memory problems, rather than to problems in retrieving the right word, which often is the case when one of the participants has aphasia. In example 5, the couple is also talking about their children, but here the wife asks the husband about their names. It is obvious that she knows the answer to the question, and the sequence turns into a learning event.

Example 5.

$\mathrm{M}=$ participant with aphasia, $\mathrm{K}=$ his wife, without aphasia, $\mathrm{S}=$ interviewer

69. K: we have two children

70. M: [yeah right so?]

71. S: [yeah?]

72. K: yes what are they called

73. M: yes: you (2.0)

74. K: ${ }^{\circ} v i{ }^{\circ}$

75. M: (i thi-) i recall it? but

76. K: ye:s

77. M: i recall [(bä)] (.) [(something on)]

78. K: [m:] [vi-]

79. M: ((breathing with a weak tone))

80. K: vi-

81. M: oh yes right

82. K: [vi-]

83. M: [vä vä]

84. K: vi-

85. M: tor

86. K: vik[tor?]

87. M: [tor]

88. K: and $a-$

89. M:

90. K: $\mathrm{m}:$ ?

91. S: m:?

92. K: are they called

93. M: .hha

In this example, the repair sequence starts with the TIB produced by the PWA (line 73) when he has problems in saying the names of the couple's children. His wife, who also posed the question (line 72), prompts him with the first syllable (line 274), and the PWA responds by saying that he recalls it (line 75 and 77), although not producing the names, resulting in further prompting by the wife (line 78, 80, 82, and 84 ). In line 85 , the PWA completes the name of the son, which is confirmed by the wife (line 86) and the PWA (line 87). The wife 
also prompts the first syllable of the daughter's name (line 88), which immediately is completed by the PWA (line 89), and the sequence is ended by acceptance of the PWA, the wife, and the interviewer (lines 90-93). In the quantitative analysis this would be calculated as a TIB in the format of a question initiated by the PWA followed by negotiation and acceptance by confirmation.

\section{Discussion}

The aim of the present study was to identify problems with communication in interaction involving PWA and PWD through the study in a collaborative interview setting with their significant others. In particular, interactional practises used in order to resolve problems caused by specific symptoms were compared. The results of the present study demonstrated that repair sequences were frequent in interaction involving people with aphasia, and even more so in interaction involving people with dementia. In general it was the PWA/PWD that initiated the repair sequence more often than the spouse, thus keeping to the general rule of a preference for self-initiated repair compared to other-initiated repair (Schegloff, Jefferson \& Sacks, 1977).

The most frequently evoked TIB for PWD was “questions”, while “word search” was most common for PWA. There were also some consistent patterns regarding type of TIB, and the type of repair that follows; errors commonly resulted in corrections for both groups, questions commonly resulted in direct or negotiated answers, and word searches commonly resulted in some kind of suggestion of a word. The results also demonstrated that most repair sequences also had an acceptance phase, most frequently by confirmation or repetition. 
In the present data, there were also a number of sequences where the trouble source needed negotiation over longer stretches of turns in order to be resolved. For the aphasia dyads $50 \%$ of the repair sequences were longer than three turns, and for the dementia dyads, $65 \%$ of the repair sequences were longer than three turns. The repair trajectories demonstrated that for both groups the interactional repair was a collaborative process, where both spouses were actively involved. It is also worthy of note, that PWD initiated repair, something that has been described as problematic in previous research (Orange et al., 1996). In conversations that involve PWD repairs are often elaborated and involve many turns (Orange et al., 1996). In many cases attempts to self-repair by the person with dementia may require quite an extended number of turns involving the need for repair support by the other person. It has been suggested that it may be meaningful to reconceptualise the idea of repair in interaction involving persons with dementia as extended, collaborative repair episodes involving more than three interactional turns (Hydén, 2014). In the present material, it was also found that although there was a preference for self-repair most PWA/PWD were unable to complete or pursue a self-repair without involving the healthy spouse. However, the variation was significant both within and between groups, pointing to the need for further investigation in order to obtain conclusive results.

The progression of disease is quite different between dementia and aphasia. Aphasia typically has a sudden onset, while dementia often develops gradually, and aphasia is typically a rather static condition while dementia progresses. This difference in onset patterns may underlie the difference between the repair trajectories in interaction involving PWD and PWA. It is reasonable to assume that if the problems start very suddenly, there is an acute need to solve communication problems that may lead to rather efficient repair strategies. If the problems 
develop slowly, as in dementia, the need for repair may increase in a more subtle way leading to repair strategies that stretch over longer conversational sequences.

\section{Limitations}

There is a possibility that the results of the present study were limited by the fact that there were some differences in the external context of the interviews so that some of the interviews with the PWA were carried out in their homes, while all of the interviews with the PWD were carried out in the clinic. This difference, however, mainly affects the ease of participants, and probably the quality of repair to a lesser extent. Another caveat of the present study regards the relatively small number of participants, and the results can therefore not be applied to all people with aphasia or dementia.

\section{Future directions}

The comparison between aphasia and dementia regarding interactional patterns is important, and it adds to the knowledge about which mechanisms that are used in order to resolve problems in communication. In future research it would be of interest to compare not only repair sequences but also to identify different patterns of well functioning strategies. In future projects it would also be possible to further develop intervention programmes targeting interaction for PWD.

\section{Conclusion}

Today, there are a number of conversational partner training programs for PWA (SimmonsMackie, Raymer, Armstrong, Holland \& Cherney, 2010), but there are no specific conversational parter training programs for PWD. However, the active involvement of the 
conversational partners in trouble solving sequences in interaction with PWD demonstrated in the present study indicates that this would be fruitful. As in for example the SPPARC program for PWA (Lock, Wilkinson \& Bryan, 2008), the intervention for PWD could depart from analysis of interactional patterns, leading to interactional advice for conversational partners. Direct intervention targeting the use of supportive strategies for conversational partners, would probably be fruitful for PWD, as it has been shown to be for PWA (Kagan Black, Duchan, Simmons-Mackie \& Square, 2001). There are also promising results from studies on intervention targeting communication, according to a literature review by Eggenberger, Heimerl and Bennet (2012). It was concluded that communication skills training in dementia care significantly improves the quality of life and wellbeing of people with dementia and increases positive interactions in various care settings. Communication skills training also shows significant impact on professional and family caregivers’ communication skills, competencies, and knowledge.

In a case study by Murray (1998), a woman with progressive aphasia (semantic dementia), participated in interaction with a spouse. It was demonstrated that pre intervention repair strategies were restricted to mainly repetition, but that both the woman with progressive aphasia and her spouse could use more various repair patterns, with for example elaborated, responses post intervention (Murray, 1998). In another case study of communicative effectiveness (Wong, Raksha, Chapman, Rackley \& Zientz, 2009), it was concluded that for a man with semantic dementia his speech output was drastically reduced with disease progression. However, he was able to achieve various functions of communication also in later stages with support from his communication partner. However, intervention targeting communication and interaction would also need interactionally focused language assessment, as well as education of staff and family members, in order to be used in clinical practice. 


\section{Acknowledgements}

We are grateful to the participants for their participation in this study. We are also grateful to Dina Asaid and Sofia Erenmalm for help with data gathering. The research reported in this study was supported by a grant from the Swedish Riksbankens Jubileumsfond (M10-0187:1). The procedures followed in carrying out this study were in accordance with the ethical standards of the responsible committee of human experimentation, and with the Helsinki Declaration of 1975 as revised in 1983.

\section{References}

Aaltonen, T., \& Laakso, M. (2010). Halting aphasic interaction: Creation of intersubjectivity and spousal relationship in situ. Communication \& Medicine, 7, 95-106.

Allen, M., McGrenere, J. \& Purves, B. (2008). The field evaluation of a mobile digital image communication application designed for people with aphasia. ACM Transactions on Accessible Computing, 1(1), Article 5. 
Alm, N., Dye, R., Gowans, G., Campbell, J., Astell, A. \& Ellis, M. (2007). A communication support system for older people with dementia. IEEE Computer, 35-41.

Astell, A. J., Ellis, M., Bernardi, L., Alm, N., Dye, R., Gowans, G. \& Campbell, J. (2010). Using a touch screen computer to support relationships between people with dementia and caregivers. Interacting with Computers, 22, 267-275.

Bamberg, M., \& Georgakopoulou, A. (2008). Small stories as a new perspective in narrative and identity analysis. Text and Talk, 28(3), 377-396.

Barnes, S. \& Ferguson, A. (2014). Conversation partner responses to problematic talk produced by people with aphasia: Some alternatives to initiating, completing, or pursuing repair. Aphasiology, DOI: 10.1080/02687038.2013.874547.

Bratman, M. E. (1992). Shared cooperative activity. Philosophical Review, 101 (2):327-341

Bremer, K., Broeder, P., Roberts, C., Simonot, M. \& Vasseur, M. (1987). Ways of achieving understanding. In: C. Purdue (Ed.) Adult Language Acquisition: Cross-linguistic Perspectives (Vol 2) Cambridge: Cambridge University Press, pp. 153-195.

Bourgeois, M. S. \& Hickey, E. M. (2009). Dementia. From diagnosis to treatment - a functional approach. New york, NY: Psychology press.

Bourgeois, M. S., Dijkstra, K., Burgio, L. D. \& Allen, R. S. (2004). Communication skills training for nursing aids of residents with dementia: The impact of measuring performance. Clinical Gerontologist, 27(1/2), 119-138. 
Burgio, L. D., Allen-Burge, R., Roth, D.L. Bourgeois, M. S., Dijkstra, K., Gerstle, J., Jackson, E. \& Bankester, L. (2001). Come talk with me: Improving communication between nursing assistants and nursing home residents during care routines. The Gerontologist, 41, 449-460.

Drew, P. (1997) "Open” class repair initiators in response to sequential sources of troubles in conversation. Journal of Pragmatics, 28, 69-101.

Clare, L. (2008). Neuropsychological Rehabilitation and People with Dementia. Hove: Psychology Press.

Clark, H. H. (1996). Using language. Cambridge: Cambridge University Press.

Clark, H. H., \& Schaefer, E. F. (1987). Concealing one's meaning from overhearers. Journal of Memory and Language , 26, 209-225.

Clark, H. H., \& Schaefer, E. F. (1987). Concealing one's meaning from overhearers. Journal of Memory and Language , 26, 209-225.

Clark, H.H. \& Schaefer, E.F. (1989). Contributing to discourse. Cognitive Science, 13, 259294.

Code, C. \& Petheram, B. (2011) Delivering for aphasia. International Journal of Speech Language Pathology 13, 3-10. 
Eggenberger, E., Heimerl, K. \& Bennet, M.I. (2012). Communication skills training in dementia care: A systematic review of effectiveness, training content, and didactic methods in different care settings. International Psychogeriatrics, Available on CJO doi:10.1017/S1041610212001664

Ferguson, A. (1993). Conversational repair of word-finding difficulty. In: M. L. Lemme (Ed.), Clinical Aphasiology, (Vol 21) Austin, TX: Pro-Ed., pp. 299-310.

Ferguson, A. (1994). The influence of aphasia, familiarity and activity on conversational repair. Aphasiology, 8, 143-157.

Ferguson, A. (1998). Conversational turn-taking and repair in fluent aphasia. Aphasiology, 12(11), 1007-1031.

Gilbert, M. (2009). Shared intention and personal intentions. Philosophical Studies, 144, 167187.

Goodwin, C. (1995). Co-constructing meaning in conversations with an aphasic man. Research on Language and Social Interaction, 37, 233-260.

Green, N. L., Guinn, C. \& Smith, R. W. (2012). Assisting social conversation between persons with Alzheimer's disease and their conversational partners. NAACL-HLT Workshop on Speech and Lnaguage Processing for Assistive Technologies (SPLAT), 37-46. 
Hallgren, K.A. (2012). Computing Inter-Rater Reliability for Observational Data: An Overview and Tutorial. Tutor Quant Methods Psychol. 2012; 8(1): 23-34.

Hengst, J. (2003). Collaborative referencing between individuals with aphasia and routine communication partners. Journal of Speech, Language, and Hearing Research, 46(4), 831848.

Hydén, L-C., Plejert, L., Samuelsson, C. \& Örulv, L. (2013). Becket-nesque stories: Feedback and common ground in conversational storytelling involving people with alzheimer's disease. Journal of Interactional Research in Communication Disorders. 4.2, 211-249.

Kagan, A., Black, S., Duchan, J., Simmons-Mackie, N. \& Square, P. (2001). Training volunteers as conversation partners using "Supported Conversation for Adults with Aphasia" (SCA): A controlled trial. Journal of Speech Language and Hearing Research, 44, 624-638.

Kindell, J., Sage, K., Keady, J. \& Wilkinson, R. (2013). Adapting to conversation with semantic dementia: using enactment as a compensatory strategy in everyday social interaction. International Journal of Language and Communication Disorders, 48 (5), 497507.

Laakso, M. \& Klippi, A. (1999). A closer look at the "hint and guess" sequences in aphasic conversation. Aphasiology, 13, 345-363. 
Lindsay, J., \& Wilkinson, R. (1999). Repair sequences in aphasic talk: A comparison of aphasic-speech and language therapist and aphasic-spouse conversations. Aphasiology, 13, 305-325.

Lock, S., Wilkinson, R. \& Bryan, K. (2001). SPPARC (Supporting Partners of People with Aphasia in Relationships and Conversation): A resources pack. Bicester, UK: Speechmark Press.

Mathews, P.J., Obler, L.K. \& Albert, M.L. (1994). Wernicke and Alzheimer on the language disturbances of dementia and aphasia. Brain and Language, 46, 439-462.

Murray, L. (1998). Longitudinal treatment of primary progressive aphasia: A case study, Aphasiology, 12:7-8, 651-672.

McNeil, M.R. \& Pratt, S.R . (2001) Defining aphasia: Some theoretical and clinical implications of operating from a formal definition. Aphasiology 15, 901-911.

Milroy, L., \& Perkins, L. (1992). Repair strategies in aphasic discourse: Towards a collaborative model. Clinical Linguistics and Phonetics, 6, 27-40.

Neary, D., Snowden, J.S., Gustafson, L., Passant, U., Stuss, D., Black, S., Freedman, M., Kertesz, A., Robert, P.H.M.D., Albert, M., Boone, K., Miller, B.L., Cummings, J. \& Benson, D.F. (1998). Frontotemporal lobar degeneration: a consensus on clinical diagnostic criteria. Neurology, 51,1546-1554. 
Oelschlaeger, M. L., \& Damico, J. S. (2003). Word searches in aphasia: A study of the collaborative responses of communication partners. In: C. Goodwin (Ed.), Conversation and Brain Damage, New York: Oxford University Press. pp. 147-162.

Ochs, E., Schegloff, E. \& Thompson, S. (1996). (Eds) Interaction and Grammar. Cambridge: Cambridge University Press.

Orange, J.B., Lubinski, R. B. \& Higginbotham, J. (1996). Conversational repair by individuals with dementia of the Alzheimer's type. Journal of Speech and Hearing Research, 39, 881-895.

Perkins, L., Whitworth, A., \& Lesser, R. (1998). Conversing in dementia: A conversation analytic approach. Journal of Neurolinguistics, 11, 33-53.

Ripich, D., Ziol, E.W., \& Lee, M. M. (1998). Longitudinal Effects of Communication Training on Caregivers of Persons with Alzheimer's Disease. Clinical Gerontologist, 19, 3755.

Schegloff, E. A., Jefferson, G. \& Sacks, H. (1977). The Preference for Self-Correction in the Organization of Repair in Conversation. Language, 53, 2: 361-382.

Savundranayagam, M. Y. \& Orange, J.B. (2013). Matched and mismatched appraisals of the effectiveness of communications strategeis by family caregivers of persons with Alzheimer's disease. International Journal of Language and Communication Disorders, 49(1), 49-59. 
Small, J. A., Gutman, G., Makela, S. \& Hillhouse, B. (2003). Effectiveness of communication strategies used by caregivers of persons with Alzheimer's disease during activities of daily living. Journal of Speech, Language, and Hearing Research, 46(2), 353-367.

Tomasello, M. (2014). A Natural History of Human Thinking. Cambridge: Harvard University Press.

Ylvisaker, M., \& Feeney, T.J. (1998). Collaborative Brain Injury Intervention. Positive Everyday Routines. Clifton Park, NY: Delmar.

Watson, C. M. (1999). An analysis of trouble and repair in the natural conversations of people with dementia of the Alzheimer’s type. Aphasiology, 13(3), 195-218.

Whitworth, A., Webster, J., \& Howard, D. (2014). A cognitive neuropsychological approach to assessment and intervention in aphasia ( $2^{\text {nd }}$ ed.). Hove: Psychology Press.

Wong, S.B., Anand, R., Chapman, S.B., Rackley, A. \& Zientz, J. (2009). When nouns and verbs degrade: Facilitating communication in semantic dementia, Aphasiology, 23:2, 286-301. 
Appendix: Transcription conventions




TABLES

Table I. Participants: Code, age, years as a couple and year since stroke/dementia diagnosis

\begin{tabular}{|c|c|c|c|}
\hline Participant & Age & Years as a couple & $\begin{array}{l}\text { Years since } \\
\text { stroke/dementia }\end{array}$ \\
\hline A1 & 66 years & 32 years & 4 years \\
\hline SA1 & 65 years & & \\
\hline A2 & 59 years & 36 years & 10 years \\
\hline SA2 & 60 years & & \\
\hline A3 & 71 years & 36 years & 9 years \\
\hline SA3 & 67 years & & \\
\hline A4 & 63 years & 39 years & 15 years \\
\hline SA4 & 69 years & & \\
\hline A5 & 74 years & 53 years & 18 years \\
\hline SA5 & 75 years & & \\
\hline D02 & 63 years & 40 years & 2 years \\
\hline SD02 & 67 years & & \\
\hline D03 & 78 years & 55 years & 2 years \\
\hline SD03 & 78 years & & \\
\hline D04 & 81 years & 60 years & 3 years \\
\hline SD04 & 84 years & & \\
\hline D08 & 73 years & 47 years & 2 years \\
\hline SD08 & 74 years & & \\
\hline D10 & 81 years & 40 years & 2 years \\
\hline SD10 & 80 years & & \\
\hline
\end{tabular}

A=Person with aphasia (PWA), SA=Spouse to a PWA, D=Person with dementia (PWD), $\mathrm{SD}=$ Spouse to a PWD 
Table II: Conversational data from interactions between PWA and PWD and their spouses.

\begin{tabular}{|c|c|c|c|c|c|c|c|c|c|c|}
\hline $\begin{array}{c}\text { Coupl } \\
\text { es }\end{array}$ & $\begin{array}{c}\text { Length } \\
\text { (min:sec) }\end{array}$ & $\begin{array}{c}\text { Total } \\
\text { Turns }\end{array}$ & $\begin{array}{c}\text { Repair } \\
\text { turns }\end{array}$ & n/total & Range & ML & $\begin{array}{c}\text { MLT } \\
\mathbf{P}\end{array}$ & TIB & $\begin{array}{c}\text { TIB } \\
\text { pwd/p } \\
\text { wa }\end{array}$ & $\begin{array}{c}\text { TIB } \\
\text { spouse }\end{array}$ \\
\hline $\begin{array}{l}\text { D02 } \\
\text {. }\end{array}$ & $44: 22$ & 876 & 53 & 0,007 & $1-11$ & 3,9 & 6 & 11 & 11 & 0 \\
\hline D03 & 39:30 & 470 & 84 & 0,012 & $2-12$ & 5,1 & 5 & 16 & 14 & 2 \\
\hline D04 & $47: 29$ & 373 & 29 & 0,004 & $2-11$ & 4,1 & 5 & 7 & 5 & 2 \\
\hline D08 & $47: 59$ & 961 & 254 & 0,021 & $1-38$ & 17,7 & 4 & 26 & 26 & 0 \\
\hline D10 & $38: 58$ & 716 & 79 & 0,017 & $2-10$ & 4,5 & 6 & 17 & 13 & 4 \\
\hline A01 & 49:32 & 247 & 27 & 0,016 & $1-4$ & 2,2 & 32 & 10 & 8 & 2 \\
\hline A02 & $46: 10$ & 320 & 35 & 0,02 & $1-10$ & 3,2 & 11 & 10 & 9 & 1 \\
\hline A03 & $15: 33$ & 468 & 56 & 0,008 & 3-15 & 8,2 & 3 & 6 & 6 & 0 \\
\hline A04 & $28: 40$ & 351 & 62 & 0,02 & $2-11$ & 5,7 & 4 & 9 & 5 & 4 \\
\hline A05 & $27: 19$ & 286 & 29 & 0,019 & $1-5$ & 3,5 & 4 & 8 & 7 & 1 \\
\hline Sum & & 5068 & 708 & & & & & 120 & 104 & 16 \\
\hline
\end{tabular}

MLT=Mean length of sequence, MLTP=Mean length of turn PWD/PWA, TIB=Trouble indicating behavior. D=Person with dementia (PWD), A=Person with aphasia (PWA) 
Table III: Relation between diagnosis, who initiated the trouble-indicating behaviour (TIB) and type of TIB.

\begin{tabular}{lllll}
\hline $\begin{array}{l}\text { Initiatiator } \\
\text { To TIB }\end{array}$ & Type of TIB & Aphasia & Dementia & Sum \\
\hline Participant & Clarification request & 0 & $4(5.8)$ & $4(3.8)$ \\
& Error & $5(14.3)$ & $14(20.3)$ & $19(18.3)$ \\
& Question & $11(31.4)$ & $40(58)$ & $51(49)$ \\
& Word search & $19(54.3)$ & $11(15.9)$ & $30(28.8)$ \\
& Sum & $35(100)$ & $69(100)$ & $104(100)$ \\
Spouse & Clarification request & $2(25)$ & 0 & $2(12.5)$ \\
& Error & $5(62.5)$ & $8(61.5)$ & $13(81.3)$ \\
& Question & 0 & 0 & 0 \\
& Word search & $1(12.5)$ & 0 & $1(6.3)$ \\
& Sum & $8(100)$ & $8(100)$ & $16(100)$ \\
\hline Sum & & $\mathbf{4 3 ( 3 5 . 8 )}$ & $\mathbf{7 7 ( 6 4 . 2 )}$ & $\mathbf{1 2 0}(\mathbf{1 0 0})$
\end{tabular}

The difference between diagnostic groups was statistically significant $(\mathrm{p}=0.001)$, as measured by chi square. 
Table IV: Relation between type of trouble-indicating behaviour (TIB) and type of repair Initiatiator to

TIB

Repair made by Patient Spouse Sum

Patient (Self)

$6(5,8)$

$13(86,7)$

19 (16)

Spouse (Other)

52 (50)

$1(6,7)$

$53(44,5)$

Both engaged in

$7(6,7)$

$1(6,7)$

8 (6.7)

same repair

\begin{tabular}{llll} 
No repair & $1(1)$ & $1(6,3)$ & $2(1,7)$ \\
\hline Sum & $\mathbf{1 0 4 ( 1 0 0 )}$ & $\mathbf{1 6 ( 1 0 0 )}$ & $\mathbf{1 2 0 ( 1 0 0 )}$
\end{tabular}

The relations were all statistically significant $(\mathrm{p}<0.000)$, as measured by chi square. 
Table V: Relation between type of trouble-indicating behaviour (TIB) and type of repair.

\begin{tabular}{llllll}
\hline Repair type & $\begin{array}{l}\text { Type of TIB } \\
\text { Clarification } \\
\text { request }\end{array}$ & Error & Question & $\begin{array}{l}\text { Word } \\
\text { search }\end{array}$ & Sum \\
\hline Missing & & 1 & 1 & & 2 \\
Confirmation & $2(33)$ & 0 & $2(3.9)$ & 0 & $4(3.3)$ \\
Correction & $1(16.7)$ & $21(65.6)$ & $7(13.7)$ & $1(3.2)$ & $30(25)$ \\
Candidate & 0 & 0 & $4(7.8)$ & $1(3.2)$ & $5(4.2)$ \\
understanding & & & & & \\
Expansion & 0 & 0 & $2(3.9)$ & 0 & $2(1.7)$ \\
Gives answer & $1(16.7)$ & 0 & $15(29.4)$ & $17(54.8)$ & $33(27.5)$ \\
Negotiation & 0 & $7(21.9)$ & $19(37.3)$ & $11(35.5)$ & $37(30.8)$ \\
Question & 0 & $2(6.3)$ & $1(2)$ & $1(3.2)$ & $4(3.3)$ \\
Repetition & $2(33,3)$ & $1(3.1)$ & 0 & 0 & $3(2.5)$ \\
\hline Sum & $\mathbf{6 ( 1 0 0 )}$ & $\mathbf{3 2}$ & $\mathbf{5 1}(\mathbf{1 0 0})$ & $\mathbf{3 1}$ & $\mathbf{1 2 0}$ \\
\hline
\end{tabular}

The relations were all statistically significant $(\mathrm{p}<0.000)$, as measured by chi square. 
Table VI: Repair and acceptance.

\begin{tabular}{llllll}
\hline $\begin{array}{l}\text { Type of } \\
\text { repair }\end{array}$ & $\begin{array}{l}\text { Type of } \\
\text { acceptance } \\
\text { None }\end{array}$ & Confirmation & Repetition & $\begin{array}{l}\text { Repetition } \\
\text { and }\end{array}$ & Sum \\
& & & & \\
& & & & \\
& & & & \\
confirmation & \\
\hline None & 0 & $1(1.4)$ & $1(7.7)$ & 0 & $2(1.7)$ \\
Confirmation & $1(2.9)$ & $3(4.3)$ & 0 & 0 & $4(3.3)$ \\
Correction & $11(31.4)$ & $17(24.3)$ & $2(15.4)$ & 0 & $30(25)$ \\
Candidate & $2(5.7)$ & $3(4.3)$ & 0 & 0 & $5(4.2)$ \\
understanding & & & & & $2(1.7)$ \\
Explanation & 0 & $1(1.4)$ & 0 & $1(50)$ & $33(27.5)$ \\
Gives answer & $5(14.3)$ & $18(25.7)$ & $9(69.2)$ & $1(50)$ & $37(30.8)$ \\
Negotiation & $13(37.1)$ & $24(34.3)$ & 0 & 0 & $4(3.3)$ \\
Question & $2(2.9)$ & $2(2.9)$ & $1(7.7)$ & 0 & $3(2.5)$ \\
Repetition & $1(1.4)$ & $1(1.4)$ & 0 & 0 & $120(100)$ \\
\hline Sum & $35(100)$ & $70(100)$ & $13(100)$ & $2(100)$ & \\
\hline
\end{tabular}

